\title{
Numerical analysis of bed elevation and bank line changes at the confluence of Nakdong and Geumho Rivers in Korea
}

\author{
E.K. Jang \\ Korea Institute of Civil Engineering and Building Technology \\ U. Ji \\ Korea Institute of Civil Engineering and Building Technology/Korea University of Science and Technology
}

\begin{abstract}
The river confluence forms complex flow pattern because of different inflow discharges from the main stream and tributary. Complex flow feature at the confluence affects geomorphological changes. Especially rapid and continuous flow changes produce unstable condition in the channel geometry. Therefore, it is important to analyze geomorphological changes such as bank erosion and deposition as well as bed changes at the confluence channel for river maintenance and management, especially before and after the construction of river structures like weirs and bridges. Progressive erosions including headcutting and bank erosion are expected in the confluence in Nakdong River and Geumho River, Korea because a large weir (GangjeongGoryeong Weir) has been constructed in the upstream channel during Four Major Rivers Restoration Project. Therefore, flow changes, bed elevation changes, and bank-line changes have been simulated in this study using the 2-dimensional numerical model of CCHE2D (Center for Computational Hydroscience and Engineering 2-Dimension) to analyze variations after the weir construction. The largest flood event before and after the weir construction is selected for hydraulic condition in the model. The measured data for flow and sediment discharge at the Dongchon Station in the Geumho River and Waegwan Station in the Nakdong River have been used for boundary conditions. Numerical simulations of this study reproduce similar variation to the actual condition regarding geomorphological changes in the river confluence. The study results should provide fundamental information to establish many countermeasures for channel stability against excessive erosion and deposition of bed and bank at the confluence section.
\end{abstract}

\section{INTRODUCTION}

The complex flow characteristics at the confluence section have a great effect on geomorphological changes in the channel. Geomorphological changes are generated by interactions between erosion and deposition of channel bed and bank materials by flow; therefore quantitative analysis is required to examine possible changes at the river confluence for different hydraulic conditions (Jang et. al., 2016).

The main purpose of this study is numerically to analyze bed elevation and bank line changes for real study site in Korea where the 4 Major Rivers Restoration Project (4MRRP) (Ministry of Land, Infrastructure and Transport (MLIT), 2009(a)) has been performed. The 4MRRP was one of the biggest national projects, the goals of the project are to improve water resources, flood control, water quality, ecosystem, and waterfront. During the 4MRRP, 16 large scale weirs were constructed with large scale dredging. Since this project was the largest construction, it was important to understand the potential problems generated by artificial geomorphology changes. For example, bank erosion as well as bed change by typhoons or floods could cause the damage in the river environment and produce the additional sediment supply. Especially, due to the complex flow patterns and the variation of inflow discharge from the main channel and tributary, the river confluence section has many problems such as headcutting erosion, sand bar formation, severe local deposition, local scour, and bank erosion.

Therefore, in this study, numerical simulations for flow, bed change, and bank erosion have been applied for the real case using the CCHE2D (Jia et al., 2001; Wu. et al., 2001) model. The study reach is the confluence of Nakdong and Geumho Rivers in Korea. In this study site, headcut erosion is highly expected along the Geumho River due to a large amount of dredging in Nakdong River during the 4MRRP.

\section{MODELING CONDITIONS}

\subsection{Study reach}

The Nakdong River basin is the second largest one in Korea, and is located at the southeastern part of 
South Korea, where it adjoins the Han River basin in the north, the Geum River basin and the Seomjin River basin in the west, and the Taebaek Mountains in the east. The annual precipitation of the Nakdong River basin is distributed around 1,244 mm depending on the observation station. The northwestern and southwestern area of the basin have high precipitation, while the center part of the basin has relatively low precipitation (MLIT, 2009(b)). Watershed area is approximately $23,384 \mathrm{~km}^{2}$, river length is $400 \mathrm{~km}$ and slope is 0.0017 . The Geumho River is one of the tributary of Nakdoong River. The watershed area is approximately $2,053 \mathrm{~km}^{2}$, river length is $116 \mathrm{~km}$ and slope is 0.0009 . A degree of confluence of Nakdong and Geumho Rivers is 50 degree (Fig. 1).

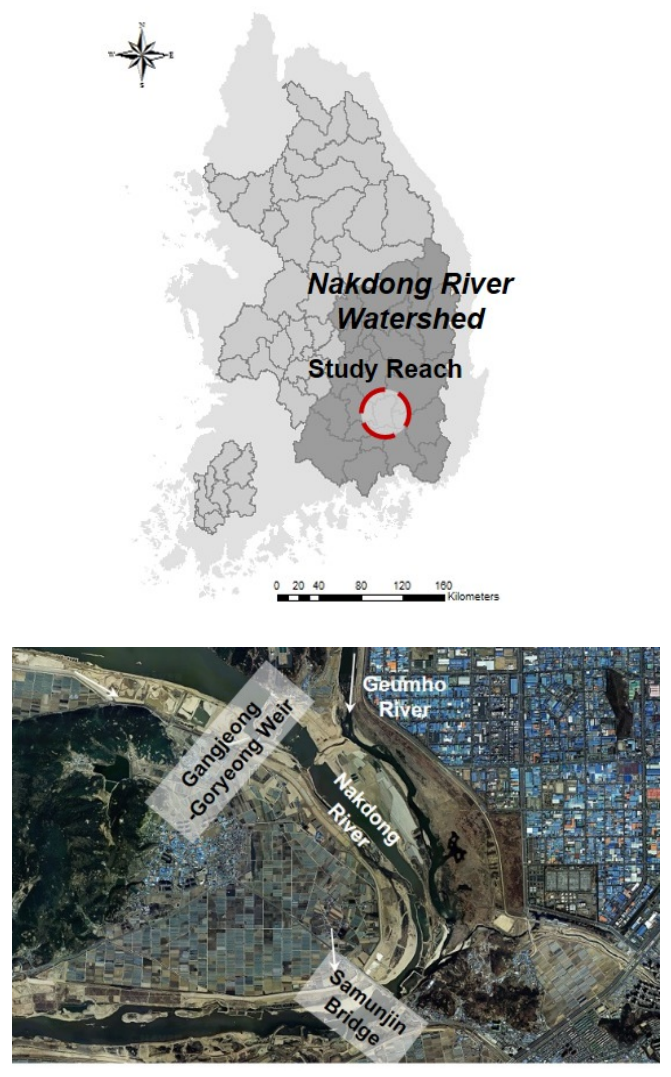

Figure 1. Study reach at the Nakdong watershed.

\subsection{CCHE2D model and input data}

The CCHE of the University of Mississippi developed the CCHE2D model to simulate the unsteady turbulent flow in open channels. The CCHE2D model is a river flow analysis model that can simulate flow and bed changes. Because many open channel flows are of shallow water problems, the effect of vertical motions is usually of insignificant magnitude. The depth integrated two-dimensional equations are generally accepted for studying the open channel hydraulics with reasonable accuracy and efficiency. In case of CCHE2D, the depth-integrated 2D momentum equations for turbulent flows in a Cartesian coordinate system are obtained by vertically integrating the $3 \mathrm{D}$
Reynolds equations (Jia, 2013). During the calculation of bed changes, for the sediment transport equation, simulation can be performed by selecting one of the following equations: modified Ackers and White (1973), modified Engelund and Hansen (1967), Wu et al. (2000), and SEDTRA Module (Garbrecht et al., 1995). For the sediment transport mode, the bed load, suspended load, and total load transport types can be selected by users. Also, it can simulate the lateral variation of channel width considering bank erosion.

The CCHE2D requires parameters such as representative grain size, flow discharge and sediment discharge etc. In this study, the representative median grain diameters $\left(d_{50}\right)$ were $0.23 \mathrm{~mm}$ along the reach, Manning's $n$ was 0.003 and the specific gravity was 2.675 . With respect to the incoming sediment, the measured data of the Waegwan station and Dongchon Station were selected. The user of the CCHE2D model can determine the sediment transport equation and the sediment transport mode, which have large effects on the calculation of bed changes. To select an appropriate sediment transport equation for the study reach, we compared several sediment transport equations with the sediment discharge data (MLIT, 2012) (Fig. 2) and $\mathrm{Wu}$ at al. (2000) formula was selected for the modeling.

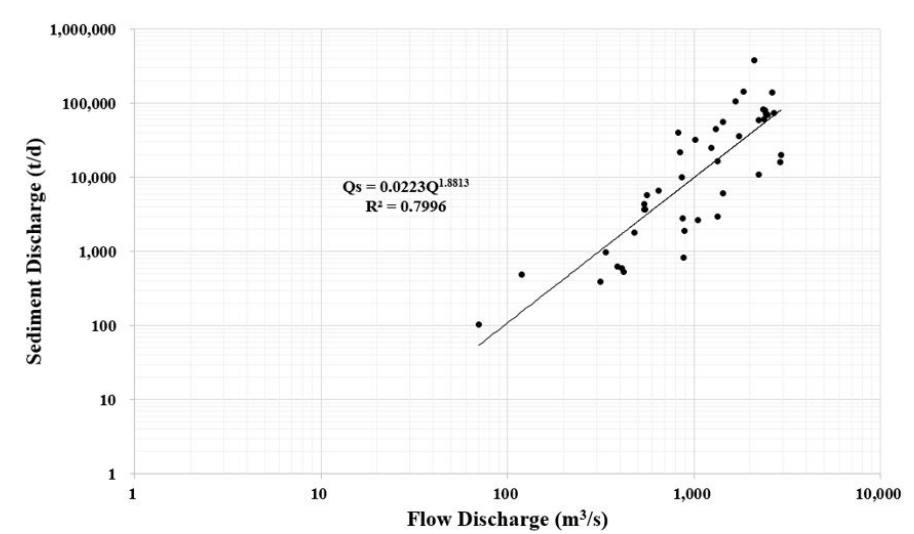

Figure 2. Sediment discharge data of the Waegwan station in Nakdong River (MLIT, 2012).

We applied inflow discharge from September 15, 2012 to September 21 (Table 1) which was the highest flood after the 4MRRP.

Table 1. Modeling Conditions.

\begin{tabular}{cccccc}
\hline \multirow{2}{*}{$\begin{array}{c}\text { Date } \\
\text { (YY-MM-DD) }\end{array}$} & \multicolumn{2}{c}{$\mathrm{Q}\left(\mathrm{m}^{3} / \mathrm{s}\right)$} & \multicolumn{2}{c}{$\mathrm{Q}_{\mathrm{s}}($ tons/day) } & Wain \\
& Stream & Tributary & \multicolumn{2}{c}{ Main } & Tributary \\
stream & stream & stream & (El.m) \\
\hline $12-09-15$ & $4,488.2$ & 53.58 & 21,056 & 85 & 13.87 \\
$12-09-16$ & $4,016.0$ & 146.8 & 18,087 & 660 & 13.42 \\
$12-09-17$ & $5,622.8$ & $1,791.3$ & 28,654 & 106,891 & 17.11 \\
$12-09-18$ & $6,294.6$ & 961.78 & 33,434 & 30,177 & 19.12 \\
$12-09-19$ & $4,710.8$ & 234.66 & 22,496 & 1,713 & 14.38 \\
$12-09-20$ & $4,646.6$ & 130.66 & 22,075 & 521 & 14.00 \\
$12-09-21$ & $4,693.6$ & 84.93 & 22,382 & 217 & 14.16 \\
\hline
\end{tabular}




\section{SIMULATION RESULTS}

\subsection{Flow simulation}

The velocity distribution were analyzed using the CCHE2D flow model. As a result of simulation, after 4 days (the highest peak discharge in Sept. 18, 2012), the velocity at the meandering section was $2.15 \mathrm{~m} / \mathrm{s}$ and $2.03 \mathrm{~m} / \mathrm{s}$ downstream of the meandering section. At the confluence area, flow velocity was around $1.4 \mathrm{~m} / \mathrm{s}$ because of relatively wide channel (Fig. 3). Especially, the velocity at the tributary was slower than the main stream.

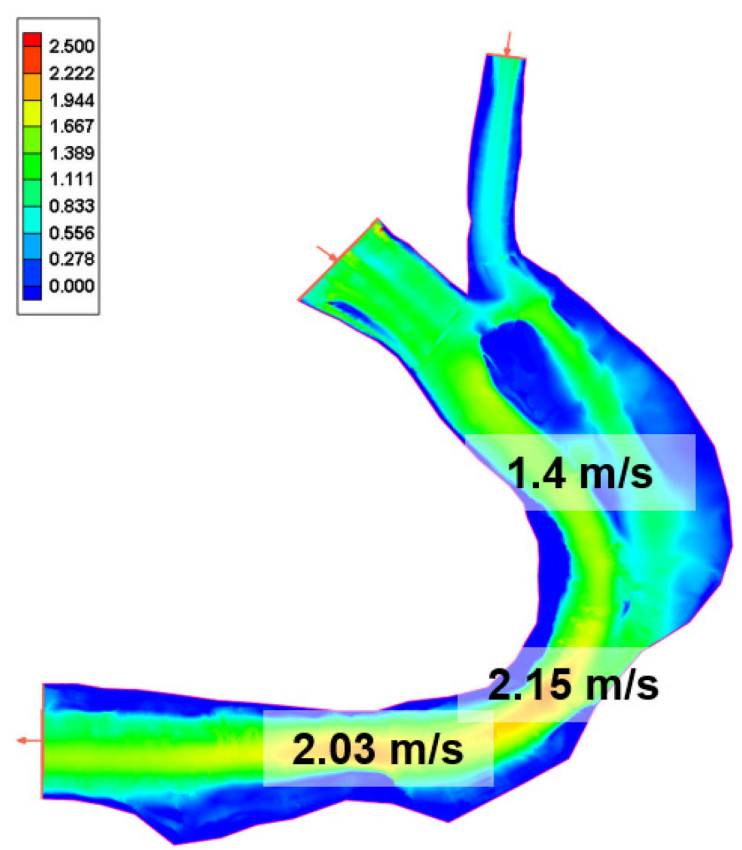

Figure 3. Flow simulation result of velocity distribution after 4 days $(\mathrm{m} / \mathrm{s})$.

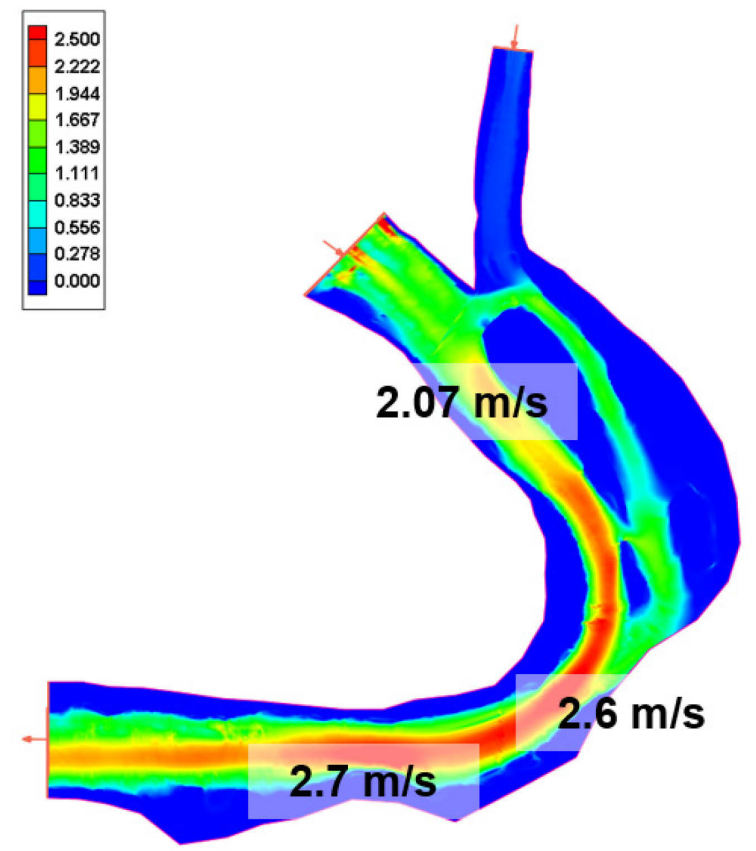

Figure 4. Flow simulation result of velocity distribution after 7 days $(\mathrm{m} / \mathrm{s})$.
On the other hand, after 7 days, the velocity at the meandering section was $2.6 \mathrm{~m} / \mathrm{s}$ and $2.7 \mathrm{~m} / \mathrm{s}$ downstream of the meandering section. Flow velocity near the confluence area was increased by $2.07 \mathrm{~m} / \mathrm{s}$ compared with the condition after 4 days. The velocity was increased due to the geographical impacts that channel width contraction after flooding event (Fig. 4).

\subsection{Bed and Bank Changes}

As a result of simulation for bed changes, after 4 days, erosion and sedimentation in the channel was not severe. The channel bed at the meandering section was eroded about $0.4 \mathrm{~m}$ (Fig. 5). As shown in Figure 5, dry section and area with low velocity distribution are generated. Therefore, the bankline at the right side channel of the meandering section has shifted inward.
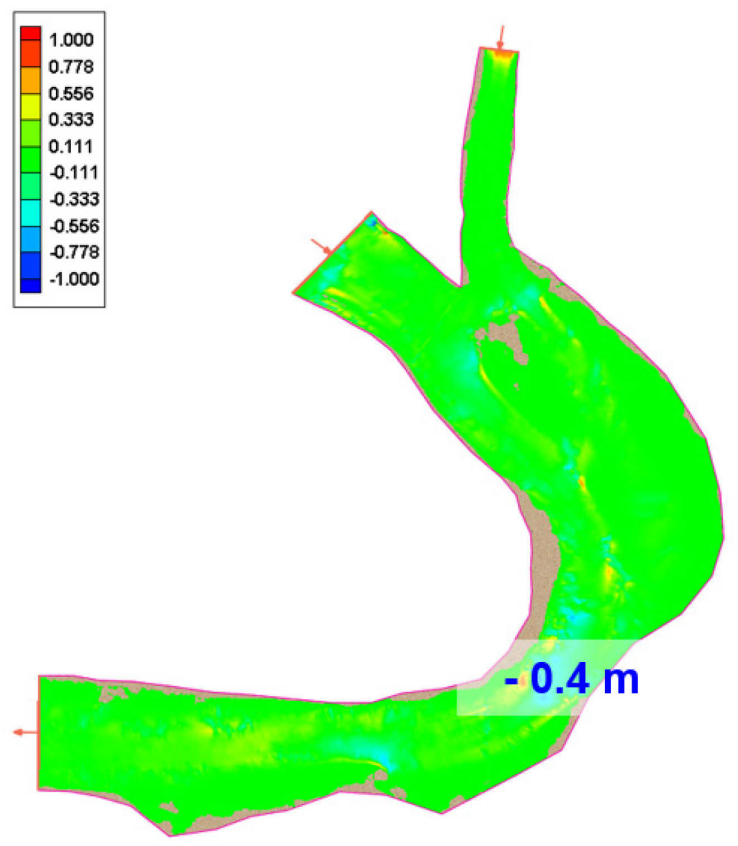

Figure 5. Bed change result after 4 days simulation (m).

As shown in Figure 6, after 7 days, sediment deposition is dominant rather than erosion across the channel. The deposited height of channel bed was $0.75 \mathrm{~m}$ at the downstream end of the study reach. However, the channel bed was eroded about $0.5 \mathrm{~m}$ in the section of the confluence and $0.9 \mathrm{~m}$ at the meandering section. By compared with the result of 4 days simulation, dry section and area near bank and at the confluence area were increased by deposition. Generally deposition was generated in the area of low flow velocity. 


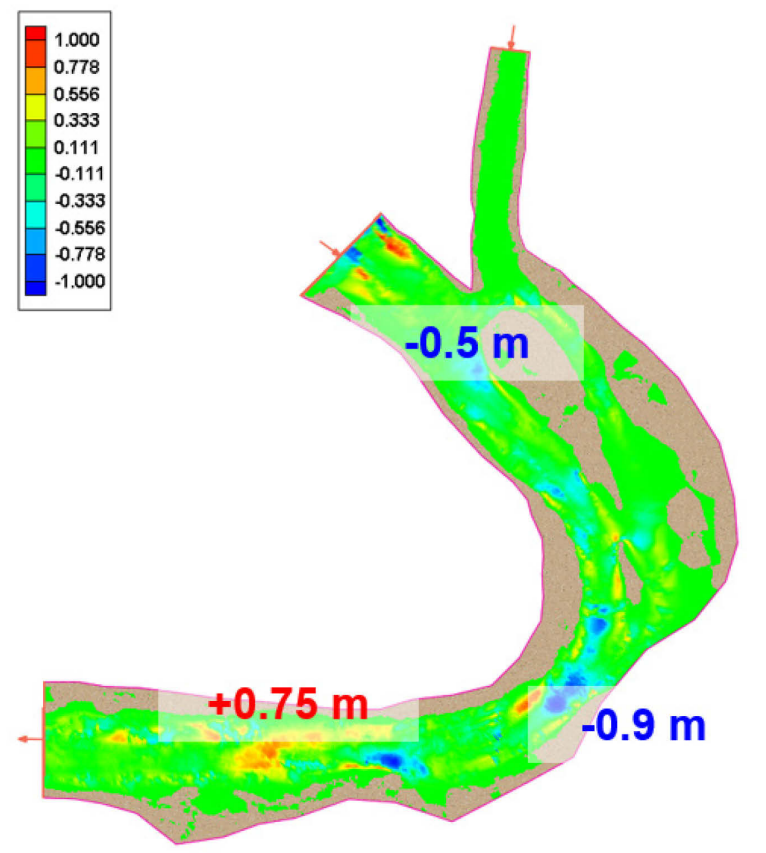

Figure 6. Bed change result after 7 days simulation (m).
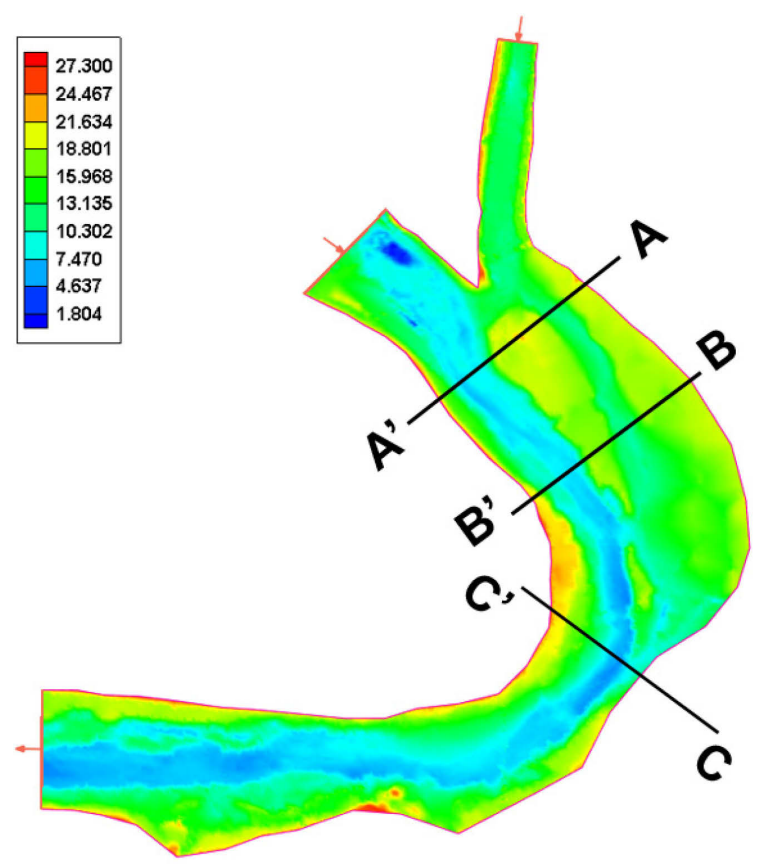

Figure 7. Selected cross-sections for the analysis of bed elevation changes.
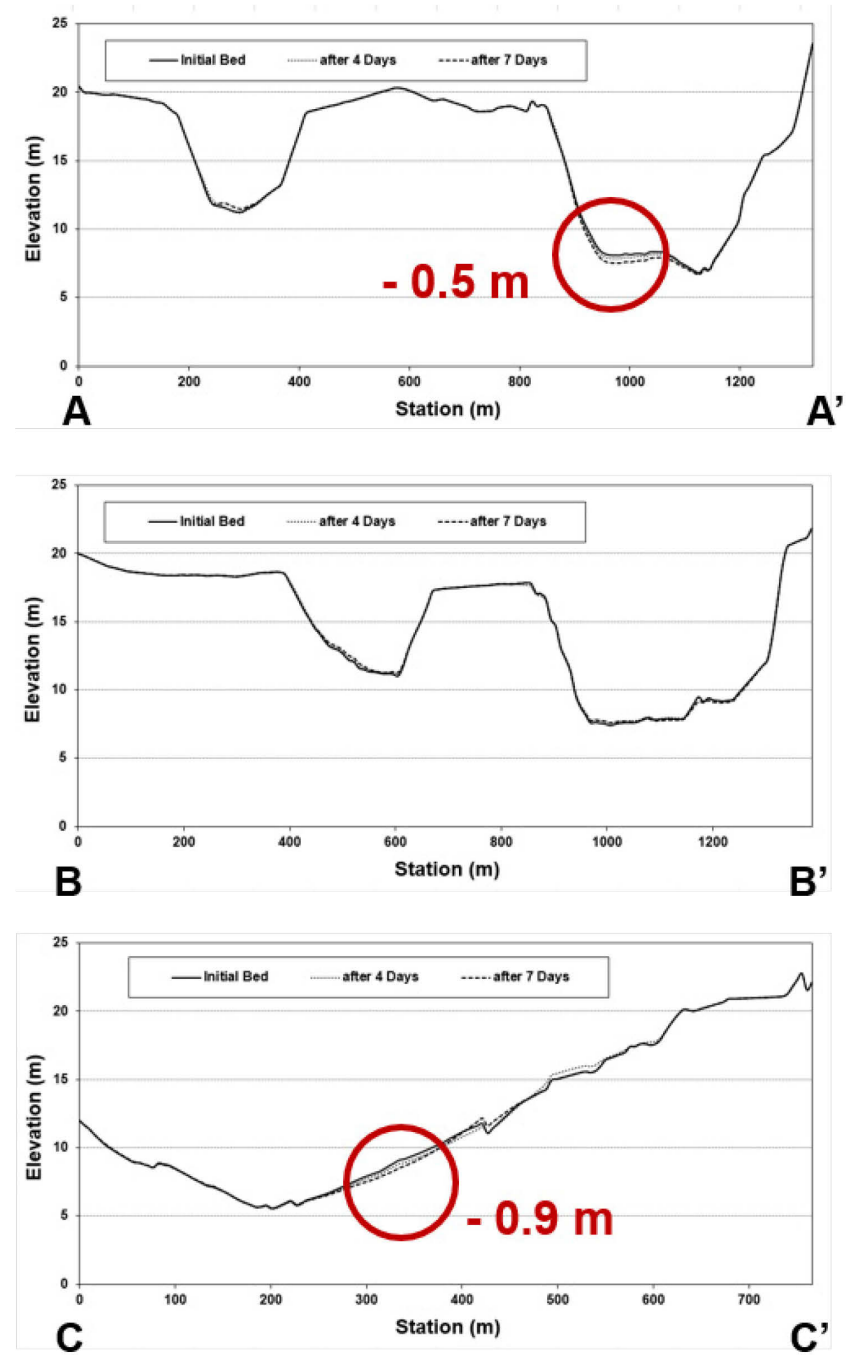

Figure 8. Comparison of cross-sections.

For more comparisons by simulation time, crosssections of initial condition and simulation results after 4 and 7 days were plotted in Figure 8 for the selected sections as shown in Figure 7. At the crosssection A-A', $0.5 \mathrm{~m}$ of bed degradation occurred at the right side channel. The largest erosion $(0.9 \mathrm{~m})$ occurred at the cross-section C-C' downstream of the confluence, especially in the middle point of the cross-section. 


\section{CONCLUSIONS}

In this study, numerical modeling was performed for the confluence section of Nakdong and Geumho Rivers where fluvial geomorphological change was expected. Based on the simulation results, bed changes are continuously expected in this channel due to inflow variation from the tributary. In the meandering section downstream of the confluence area, it is predicted that flow is accelerated and bed erosion is increased. It is indicated that the complexity of geomorphological characteristics in the confluence section affects to flow patterns and flow changes also become a main factor of erosion and sedimentation in the channel.

\section{ACKNOWLEDGEMENT}

This research was supported by a grant (11-TI-C06) from Advanced Water Management Research Program funded by Ministry of Land, Infrastructure and Transport of Korean government.

\section{REFERENCE}

Ackers, P. \& White, W.R. 1973. Sediment transport: New approach \& analysis. Journal of hydraulics division, ASCE, 99(11): 2041-2060.

Engelund, F.A. a Hansen, E. 1967. Monograph on sediment transport in alluvial streams. Teknisk Forlag.

Garbrecht, J., Kuhnle, R.A. \& Alonso, C.V. 1995. A sediment transport formulation for large channel networks, Journal of soil and water conservation, 50(5): 517-579.

Jang, E.K. \& Ji, U. 2016. Case study: numerical analysis of bed change and bank erosion at the confluences in Namhan and Nakdong rivers, South Korea. 11th International Symposium on Ecohydraulics 2016, Melbourne, Australia

Jia, Y. \& Wang. S, S.Y. 2001. CCHE2D:Two-dimensional hydrodynamic and sediment transport model for unsteady open channel flows over loose bed, NCCHE-TR-2001-1, School of engineering the University of Mississippi, USA.

Jia, Y. 2013. CCHE-GUI-Graphical Users Interface for NCCHE Models User's Manual - Version 4.x, NCCHETR-2013-01, School of engineering the University of Mississippi, USA.

Ministry of Land, Infrastructure and Transport and Maritime Affairs. 2009a. Basic plan for river maintenance of Nakdong River. Ministry of land, transport and maritime affairs (MLTMA), Korea.

Ministry of Land, Infrastructure and Transport and Maritime Affairs. 2009b. Master plan report of 4-river Restoration Project, Ministry of land, transport and maritime affairs (MLTMA), Korea.

Ministry of Land, Infrastructure and Transport and Maritime Affairs. 2012. Hydrology Research Report, Ministry of land, transport and maritime affairs (MLTMA), Korea.

Wu, W. 2001. CCHE2D sediment transport model (version 2.1), NCCHE-TR-2001-3, School of engineering the university of Mississippi, USA.

Wu, W., Wang, S., S.Y. \& Jia, Y. 2000. Nonuniform sediment transport in alluvial river, Journal of hydraulic research, 38(6): 427-434. 